\title{
The Relationship between Knowledge Management and Organizational Learning with the Effectiveness of Ordinary and Smart Secondary School Principals
}

\author{
Zahra Khammar (Corresponding Author) \\ 1Science and Research Branch, Islamic Azad University, Zahedan, Iran \\ E-mail: Khammar_m@yahoo.com \\ Alireza Heidarzadegan \\ Faculty of Education and Psychology, University of Sistan and Baluchestan, Iran \\ Seyed Reza Balaghat \\ Faculty of Education and Psychology, University of Sistan and Baluchestan, Iran \\ Hadi Salehi \\ Faculty of Literature and Humanities, Najafabad Branch, Islamic Azad University, Najafabad, Isfahan, Iran
}

Received: 15-04- 2013

doi:10.7575/aiac.ijels.v.1n.1p.23
Accepted: 01-06- 2013

Published: 01-07- 2013

URL: http://dx.doi.org/10.7575/aiac.ijels.v.1n.1p.23

\begin{abstract}
This study aimed to investigate the relationship between knowledge management and organizational learning with the effectiveness of ordinary and smart high school principals in Zahedan Pre-province. The statistical community of this research is 1350 male and female teachers teaching in ordinary and smart students of high schools in that 300 ones were selected by stratified random sampling based on Morgan Table and the rate of the principals' knowledge management was measured using Phong's Modified Questionnaire (2009). Neefe's Modified Questionnaire is also used for organizational learning and the effectiveness of principals has been measured using Pokharel's Revised Questionnaire (2005). The reliability coefficients of the questionnaires were achieved 0.92 in knowledge management, 0.93 in organizational learning and 0.88 in its effectiveness using Cronbach's alpha. In addition, their validity was confirmed by the instructors. The obtained data were analyzed using statistical indicators such as mean, Pearson correlation coefficient, independent t-test as well as regression in SPSS software and the final model was confirmed using structural equations in LISREL software. The results obtained in this study showed that there is a significant relationship between knowledge management and organizational learning in ordinary and smart schools. In other words, organizational learning increases by the increase of knowledge management in that this increase in smart schools is more that of ordinary ones. The general relationship between knowledge management and organizational learning with the effectiveness of ordinary and smart schools principals was approved. The outcomes obtained regarding gender variable indicate a higher average of male principals in comparison to female principals.
\end{abstract}

Keywords: Knowledge Management, Organizational Learning, Effectiveness, Effective Management

\section{Introduction}

The current era is the age of accelerating and unpredictable changes. Management status in our society reflects an imbalance among the increasing complexity of organizations as well as the inability of these organizations to predict and cope with these changes and complexities (Argot, 2003). To deal with documental and environmental threats out of the potential opportunities, organizations must identify their own internal capacities and capabilities, repair their weaknesses and enhance their weaknesses. Management problems and issues are so complex and intertwined that it is not easy to diagnose the problems and the human nature of these organizations and the complexity of employees' behavior increases this complexity (Khanalizade, 2010). In an organization that learning is emphasized, the employees consider for themselves high goals and learn how to create the desired results and finally obtain sufficient profits that is necessary to survive and maintain their positions (Beikzade and Fardiazar, 2010). Environmental changes have led organizations to constantly follow the best practices and approaches to be adapted to their environment (Daft, 2008). Hence, they will be achieved to competitive benefits and one way to achieve sustainable competitive advantages is the emphasis on knowledge management and continuous organizational learning of the employees to achieve organizational goals with maximum effectiveness (Saedi \& Yazdani, 2009). Organizational learning and knowledge management are two related concepts that have always attracted the attention of many theorists and managers of organization and management since the past two decades (Lawrence, 2002). 
As human beings benefit from learning capacity and capability as well as produce new insights and concepts, the organizations have such capabilities. However, organizational learning occurs when employees use their own learning power to solve common organizational problems (Ghorbanizade, 2008). Knowledge management is associated with creating and developing knowledge assets of an organization with an approach to go beyond organizational goals and requires all the activities that are related to identification, collaboration and knowledge creation (Martin, 2009). This requires systems for the creation and maintenance of knowledge resources, knowledge facilitation and organizational learning. In this regard, those organizations are successful that view knowledge as an asset and develop organizational values and norms that cause supporting the creation and collaboration of knowledge. Knowledge management deals with creating, sharing and diffusing knowledge in individual's thought, mind and imagination and tries to collect and manage scattered knowledge in individuals working in organization in order to a new knowledge be created (Saedi and Yazdani, 2009). Therefore, to transcend from other organizations, an organization should develop human resources and increase the amount of available information and knowledge (Nanda, 2007). The employees and knowledge they have are very valuable resources for the organization. It is the knowledge and how to learn these strategic resources of the organization that should be managed and developed. Hence, organizational learning and knowledge production have been emphasized in recent years (Sobhaninejad, 2008). Organizational learning is a dynamic process that enables organization to be quickly adapted to the changes. This process includes producing new knowledge, skills and behaviors. Organizational learning is the main way to create knowledge work and improve the efficiency of the organization. A successful organization should be therefore dynamic in learning (Khanalizade, 2010). This is while organizational learning goals and knowledge management as well as their relationships from the perspective of some scholars are as follows:

Organizations learn how to modify and improve their adaptability power and efficiency in the face of environmental changes. Moreover, learning enables organizations to respond faster and more efficient against complex and dynamic environment. It also takes time to learn, but when the learning process initiates, it will be appeared in doing their works with a good nutrition and organization's members (Beykzade and Fardiazar, 2010). Therefore, it can be said that Newman follows four objectives in knowledge management in his introduced model (Noures, 2008): i) knowledge creation, ii) knowledge maintenance, iii) knowledge transfer, iv) knowledge utilization.

Organizational learning has been defined as the capability of the organization to maintain and improve its performance based on past experience and consider this capability as the ability to acquire and exploit tacit and explicit knowledge to collaborate and use it in the organization. Moreover, the integration between knowledge management and learning with the objectives of efficiency promotion is necessary (Yaghoubi, 2009).

Education is the basis and foundation of cultural, social, economic and political development in each society which is considered as the growth industry in most countries and allocates the highest governmental budget after defense affairs (Radan, 2002). Since a substantial part of the activities in education is carried out in schools, they have a special place as a critical and important social system. Unless the effective principals are supported in schools, they would be able to do the risk-taking responsibilities behooves them as much the best way as possible (Saban, 2001). In the official education, the tool, construction or a special work to successfully implement the objectives is performed through an effective management that requires true understanding and recognition of complex and various aspects of organizations (Hajipour, 2007). Since the ultimate objective in knowledge management is to increase efficiency and effectiveness, it can be found out why organizations have an interest on knowledge management and knowledge and this management cannot be implemented in case it is related to organizational learning approach (Norouzaian, 2010).

Knowledge management literature is also linked to organizational learning. The concept of knowledge management is formed from the studies associated with organizational learning so that organizational learning requires knowledge management (Reshme, 2009). Learning is crucial as the key for the conversion (the ability to adapt oneself to changing circumstances) and revival of the organization (Toumi, 2007). Learning is important for the organizations, as the internal inclination to identify, collect and obtain new knowledge enables organizations to make their staff ready to reach their goals. In fact, when learning is internalized in the staff behavior, they then will be able to understand their contribution for the collaboration with the organization (Beykzade and Fardiazar, 2010).

Conducting the present study makes it clear that knowledge management can be used more optimally in the educational organizations and increases organizational learning. Accordingly, studies like the current one on studying the relationship between knowledge management and organizational learning with the effectiveness of school principals (ordinary and smart schools) can be very important. To have an effective management, it requires to have some personality traits and our actions and behaviors should also be correct along with as well as have special skills. We are able to investigate the relationship between these traits and behaviors with a detailed analysis of the effective characteristics and management behaviors. For example, a manager who is self-confidant and courageous usually has more stability in his/her behavior when faced with difficult conditions. As we know, leadership is a part of management and is somehow the process of influencing in others to achieve specific goals.

Managers influence others with their power. The behaviors and skills of successful managers are as follows: technical competence, courage and integrity, the attitude towards people and situations, steadfastness in the face of hardships, quick recompense of failures and protection and distribution of power in the range of management. Managers are classified in terms of the power they preserve for themselves. For example, the managers who adopt participatory style are classified into three branches as public (democratic), social and consulting managers. Participatory style has the greatest effect in some situations in which people are under the supervision of a qualified manager who are motivated 
enough to do their job satisfaction (Chung, 2008). Various studies have shown that effective managers often support the individuals who are under their supervision and support them in various situations. The supportive teacher encourages the learners under his supervision, and hence their morale and effectiveness will be in a higher level (Beigi, 2009).

Therefore, regarding the fact that today's society is an organizational society, human life depends on an effective management to a range of business organizations, universities, government and private agencies and many other organizations. Managers must have certain characteristics, abilities, potential competences, long experiences and knowledge as well as social, and communicative-social skills for the effectiveness and continuity of their success among many and diverse responsibilities that managers are responsible for. The first step to attain an effective management is to set goals and believe in them, have commitment to achieve them, have compatibility and similarity with them and stimulate activity towards them (Taslimi and Naderi, 2008).

To present an effective management, it also requires having some personality traits and our behaviors and actions should also be appropriate as well as have special skills. We can train effective managers with a detailed consideration of the characteristics and behaviors of effective management. To start from the first goals, we must move towards organizational learning and we require knowledge and knowledge management for appropriate learning and reach this question what relationship exists between knowledge management and organizational learning with the effectiveness of school principals.

\section{Literature Review}

A great number of domestic and foreign studies have been conducted regarding the relationship between knowledge management and organizational learning. Among the domestic studies, Shafaie (2010) conducted a survey entitled "barriers to organizational learning" using survey and Delphi method. Items such as false beliefs of principals and staff about the power of manager and their intention to retain power, non-competitive environment and systemic thinking as four obstacles of learner organization were pointed out in this study.

In their study entitled "systems and the future of knowledge management", Seyf and Alie (2010) concluded that knowledge, as a valuable resource for the organization, has a very great importance and the manager should be able to flourish the knowledge hidden in human resources by applying effective management. In a study entitled "designing continuous learning pattern among Ministry of Construction Jihad managers", Ahmadi (2010) designed an appropriate integrated model with Iran's clerical system with the combination of different experts' models including Sangeh, Argris and Garvin. The findings of his study confirmed the significant difference between the status quo and the desired one about designing special models for each critical dimension of learning among the managers.

From the study conducted by Norouzian (2010) entitled "knowledge management", it can be found that knowledge management as the need for the third millennium organizations is inevitable. Therefore, it should be dealt with in a programmed manner. In an article written by Maleki Nia (2009) entitled "knowledge management in learner organizations", it was specified that no organization can be found to be able to survive without learning. The future belongs to organizations that are able to learn take advantage of all learning practices as the best way as possible, and one of the main ways to become a learner organization is to implement knowledge management in the organization.

In another study conducted by Yaghoubi (2009) entitled "study of the relationship between organizational learning components and knowledge management in chosen hospital staff at Isfahan city", it was concluded that organizations finally need effective and efficient staff to achieve their goals for a comprehensive development and growth. The efficiency and effectiveness of organizations generally depend on the efficiency and effectiveness of human resources and employees in that organization in that dissemination of knowledge and creating a learning environment which are the main factors affecting the performance of employees. The study conducted by Reshme (2009) entitled "studying and comparing knowledge management of organizational learning in smart and ordinary schools of Tehran city" showed that there is a significant difference between organizational learning and knowledge management in smart and ordinary schools in that smart schools were above average and ordinary schools were lower than the average level.

However, among the foreign studies, Miller (2009) claimed that lack of management support, lack of support from friends and colleagues and resources, lack of feeling and meaning in the organizational learning team can have a negative impact on the success of the learning organization. Moreover, in a study entitled "understanding educational process in small and medium organizations", Zang (2006) reviewed the development of innovation through internal situation. What were achieved in this study are two distinct groups that the first one is called innovative organizations and the second one is called fixed organizations. The group of managers that are part of fixed organizations emphasized the internal part of organizations and learning was usually empirical and worked on small groups and or individual people separately. If that group is the group of innovative organizations, it has outer structure and uses encouragement for a deeper and broader learning.

In an article entitled "organizational learning in schools", Robertson (2009) focused on a valuable set of challenges, concepts, strategies and examples in this regard than executive practices and instructions to separate schools that are learning organizations. They stated key concepts such as collaboration, common goals, group commitment, creating new learning and construction in learning schools by focusing their attention on intra-institutional processes and relations as well as explaining some solutions to increase professionalism and enhancing the power of committed mentors in learning new ways to be implemented in the classroom. In another article entitled "organizational learning and strategic change", Argot (2003) approached three close and different areas between the strategic change and organizational learning. He understood the role of experience in organizational learning, transferring knowledge within 
and outside organization as well as internalizing human knowledge in the system of organizational memory and crossindividual issues as three close while different areas of organizational learning and strategic change. This study aimed to answer the following research questions:

1) Is there a relationship between knowledge management and organizational learning among ordinary and smart school principals in Zahedan city, Iran?

2) Does the general model have a significant relationship between the knowledge management and organizational learning with the effectiveness of ordinary and smart school principals in Zahedan pre-province?

3) Is there a difference between knowledge management and organizational learning and effectiveness of the principals with regard to the teachers' gender?

\section{Methodology}

Given the nature of the research questions and research objectives, descriptive-correlational method was used. The statistical community of this research includes all male and female teachers of areas 1 and 2 of Zahedan, Iran who have been working full-time in the academic year 2011-2012. Population distribution and statistical sample of teachers are given in Table 1.

Table 1. Frequency distribution and statistical sample

\begin{tabular}{|c|c|c|c|c|c|c|c|c|c|c|c|c|c|c|}
\hline \multicolumn{7}{|c|}{ Community } & \multicolumn{7}{|c|}{ Sample } & \multirow{2}{*}{$\begin{array}{c}\text { Research } \\
\text { period }\end{array}$} \\
\hline & Smart & & & rdinal & & $\overrightarrow{0}$ & & Sma & & & $\operatorname{din}$ & & & \\
\hline$\frac{3}{2}$ & $\begin{array}{l}T \\
\stackrel{T}{0} \\
\stackrel{0}{0} \\
\stackrel{0}{0}\end{array}$ & 豆 & $\frac{3}{2}$ & $\begin{array}{l}\frac{T}{9} \\
\stackrel{0}{0} \\
\frac{D}{0}\end{array}$ & $\stackrel{-1}{\stackrel{0}{D}}$ & & $\frac{3}{2}$ & $\begin{array}{l}\frac{T}{1} \\
\stackrel{0}{B} \\
\stackrel{0}{0}\end{array}$ & $\stackrel{\overrightarrow{0}}{\stackrel{0}{D}}$ & $\frac{3}{2}$ & $\begin{array}{l}\frac{T}{1} \\
\stackrel{0}{*} \\
\stackrel{0}{0} \\
\stackrel{0}{0}\end{array}$ & 官 & ث) & \\
\hline 210 & 240 & 450 & 150 & 120 & 270 & 720 & 47 & 53 & 100 & 33 & 27 & 10 & 110 & Area 1 \\
\hline 100 & 130 & 230 & 220 & 180 & 400 & 630 & 22 & 29 & 51 & 49 & 40 & 89 & 140 & Area 2 \\
\hline 310 & 370 & 680 & 370 & 300 & 670 & 1350 & 69 & 82 & 151 & 82 & 67 & 149 & 300 & Area 3 \\
\hline
\end{tabular}

In this study, sample size includes 300 secondary school teachers from 61 schools in Zahedan city to determine the relationship between knowledge management and organizational learning with the effectiveness of ordinary and smart secondary school principals of Zahedan pre-province using Morgan table. The stratified random sampling was applied.

In this study, three questionnaires namely Knowledge Management, Organizational Learning and Management Effectiveness Questionnaires were used in that Likert scale has been used in all three questionnaires (Fong, 2009 as cited in Moghimi, 2011). Knowledge Management Questionnaire has 19 questions and 5 components. To confirm the reliability of the questionnaire, 25 copies of this questionnaire were distributed among secondary school principals in Zahedan city. After being collected, it was found that Cronbach's alpha coefficient was satisfactory as shown in Table 2. Therefore, the reliability of the questionnaire was confirmed. The content validity of the questionnaire has also been approved by the experts in the field.

Table 2. Reliability coefficients of each dimension of knowledge management questionnaire

\begin{tabular}{cc}
\hline Components & Reliability questionnaire \\
\hline Knowledge acquisition & 0.72 \\
Knowledge creation & 0.78 \\
Knowledge storage & 0.71 \\
Knowledge distribution & 0.75 \\
Total & 0.92 \\
\hline
\end{tabular}

Organizational Learning Questionnaire (Neefe, 2003, as cited in Moghimi, 2011) was also used to measure principals' organizational learning. This questionnaire has 21 questions and 7 components. To confirm the reliability, 25 copies of this questionnaire were distributed among high school teachers in Zahedan city. After being collected, Cronbach's alpha coefficient was calculated as shown in Table 3. The results also confirmed the reliability of organizational learning. The content validity of this questionnaire has also been approved by professors and experts that have required validity.

Table 3. Reliability coefficients of each dimension of organizational learning questionnaire

\begin{tabular}{cc}
\hline Components & Reliability coefficient \\
\hline Common vision & 0.69 \\
Organizational culture & 0.71 \\
Teamwork & 0.75 \\
Knowledge collaboration & 0.80 \\
Systemic thinking & 0.67 \\
Leadership & 0.61 \\
Staff expertise & 0.69 \\
Total & 0.93 \\
\hline
\end{tabular}


To measure the principal's effectiveness (Pokharel, 2005, as cited in Moghimi, 2011), Management Effectiveness Questionnaire was also used. This questionnaire has 16 questions and 8 components. The reliability of Management Effectiveness Questionnaire is given in Table 4. As a result, the reliability of Management Effectiveness Questionnaire was confirmed. The content validity of this questionnaire has also been approved by the professors and experts in the field.

Table 4. Reliability coefficients of each dimension of effectiveness questionnaire

\begin{tabular}{cc}
\hline Components & Reliability \\
\hline Innovation & 0.74 \\
Agent & 0.73 \\
Guiding & 0.82 \\
Manufacturer & 0.81 \\
Coordinator & 0.70 \\
Supervisor & 0.75 \\
Facilitator & 0.82 \\
Mentor & 0.80 \\
Total & 0.88 \\
\hline
\end{tabular}

Data were analyzed using SPSS software with respect to the nature of data and measurement scale. In descriptive statistics, frequency determination, tables regulation, percentage, mean and standard deviation are used and in referential statistics, Pearson correlation coefficient and stepwise correlation coefficient were used to specify the relationship among the variables and their various aspects and also independent t-test to review gender variable. Moreover, to conform the obtained model and the rate of the effectiveness of each variable along with an integrated and balanced model among variables based on direct and indirect variables, LISREL V: 7.8 software and structural equations pattern have been used.

\section{Findings}

Research Question 1: Is there a relationship between knowledge management and organizational learning among ordinary and smart school principals in Zahedan city, Iran?

The results obtained in Table 5 indicate that there is a significant positive relationship between knowledge management and learning organizations among ordinary and smart high school principals in Zahedan city at the level of 99\%. $(\mathrm{P}<0.01, \mathrm{r}=0.94)$. In other words, the organizational learning of principals increases by the increase of their knowledge management.

Table 5. Relationship between knowledge management and organizational learning among ordinary and smart high school principals

\begin{tabular}{lcc}
\hline Variable & Organizational learning \\
\hline \multirow{2}{*}{ Knowledge management } & Correlation coefficients & 0.94 \\
& Significance level & 0.00 \\
& Number & 300 \\
\hline
\end{tabular}

Table 6 indicates that there is a significant positive relationship between knowledge management and learning organizations among ordinary and smart high school principals in Zahedan city at the level of $99 \%$. $(\mathrm{P}<0.01, \mathrm{r}=0.82)$. In other words, the organizational learning of principals increases by the increase of their knowledge management.

Table 6. Relationship between knowledge management and organizational learning among ordinary and smart high school principals

\begin{tabular}{lcc}
\hline Variable & Organizational learning \\
\hline \multirow{3}{*}{ Knowledge management } & Correlation coefficients & 0.82 \\
& Significance level & 0.00 \\
& Number & 151 \\
\hline
\end{tabular}

Table 7 indicates that there is a significant positive relationship between knowledge management and learning organizations among ordinary and smart high school principals in Zahedan city at the level of $99 \%(\mathrm{P}<0.01, \mathrm{r}=0.81)$. In other words, the organizational learning of principals increases by the increase of their knowledge management. 
Table 7. Relationship between knowledge management and organizational learning among ordinary and smart high school principals

\begin{tabular}{lcc}
\hline Variable & & Organizational learning \\
\hline \multirow{3}{*}{ Knowledge management } & Correlation coefficients & 0.81 \\
& Significance level & 0.00 \\
& Number & 149 \\
\hline
\end{tabular}

Results obtained from stepwise regression have been given in Table 8.

Table 8. Study of the relationship between knowledge management components and organizational learning among ordinary and smart school principals

\begin{tabular}{|c|c|c|c|c|c|c|c|}
\hline Step & Variable & $\mathrm{R}$ & Modified $\mathrm{R}^{2}$ & $\mathrm{~F}$ & Standard B & $\mathrm{t}$ & Sig \\
\hline 1 & Knowledge storage & 0.87 & 0.76 & 969.77 & 0.87 & 31.14 & 0.00 \\
\hline 2 & $\begin{array}{l}\text { Knowledge storage }+ \text { knowledge } \\
\text { distribution }\end{array}$ & 0.91 & 0.84 & 768.18 & 0.49 & 12.01 & 0.00 \\
\hline & & & & & 0.47 & 11.57 & \\
\hline 3 & $\begin{array}{l}\text { Knowledge storage }+ \text { knowledge } \\
\text { distribution }+ \text { knowledge } \\
\text { maintenance }\end{array}$ & 0.92 & 0.86 & 608.58 & $\begin{array}{c}0.0 \\
0.36 \\
0.25\end{array}$ & $\begin{array}{l}10.08 \\
06.51 \\
6.91\end{array}$ & 0.00 \\
\hline 4 & $\begin{array}{l}\text { Knowledge storage }+ \text { knowledge } \\
\text { distribution }+ \text { knowledge } \\
\text { maintenance }+ \text { knowledge } \\
\text { acquisition }\end{array}$ & 0.93 & 0.88 & 527.10 & $\begin{array}{c}0.0 \\
33.27 \\
0 \\
21.23\end{array}$ & $\begin{array}{l}8.6 \\
36.55 \\
6.6 \\
35.79\end{array}$ & 0.00 \\
\hline 5 & $\begin{array}{l}\text { Knowledge storage }+ \text { knowledge } \\
\text { distribution }+ \text { knowledge } \\
\text { maintenance }+ \text { knowledge }\end{array}$ & 0.94 & 0.89 & 468.51 & $\begin{array}{c}0.0 \\
27.24 \\
0.0\end{array}$ & $\begin{array}{l}6.5 \\
95.92 \\
5.6\end{array}$ & \\
\hline & acquisition + knowledge creation & & & & $\begin{array}{c}18.20 \\
0.17\end{array}$ & $\begin{array}{l}70.27 \\
5.44\end{array}$ & 0.00 \\
\hline
\end{tabular}

As Table 8 shows, in the first step, knowledge storage was the best predictor of organizational learning among ordinary and smart high school principals in Zahedan city. This variable could predict 0.76 of principals' organizational learning in ordinary and smart schools by itself. In the second step, knowledge distribution has been predicted and these two variables could predict 0.86 of the changes of organizational learning among principals; that is to say, knowledge distribution variable could predict 0.10 of the changes. In the third step, knowledge maintenance is inserted into the model in that these three variables predict 0.88 of learning organizational changes among principals, i.e. knowledge maintenance variable could predict 0.002 of the changes. In the fourth step, knowledge acquisition is inserted into the model in that this variable could predict 0.88 of learning organizational changes among principals so that knowledge acquisition could predict 0.02 of learning organizational changes among school principals by itself. In the fifth step, knowledge creation is involved into the model in that this variable predicts 0.89 of organizational learning changes among school principals so that knowledge creation variable could predict 0.01 changes of organizational learning among school principals of ordinary and smart high school principals of Zahedan city.

Research Question 2: Does the general model have a significant relationship between the knowledge management and organizational learning with the effectiveness of ordinary and smart school principals in Zahedan pre-province?

To answer this research question, the structural equations of LISREL software were used. It is noteworthy that to confirm the relationship between knowledge management and organizational learning with the effectiveness of principals, Root Mean Square Error of Approximation (RMSEA), Goodness of Fit Index (GFI), Comparative Fit Index (CFI), Non-normative Fit Index (NFI) should first have appropriate fit and second, t-value should have significant standard coefficient. Moreover, if the ratio of Chi-square to degree of freedom (df) is less than 3 and RMSEA is the root mean square error of approximation, this index is made up of model errors which its allowed limit is 0.08 , i.e. if it is less than 0.08 , it will be accepted, if less than 0.05 , it is very good and between 0.1 and 0.08 is in the moderate level. Moreover, it is better when the GFI, NFI and CFI are closer to 1 and it can be concluded that the mode has a good fitness. If t-value is bigger than 2 and smaller than -2, it will be significant at the 0.99 level. Also, concerning the model's generality of the relationship between knowledge management and organizational learning with the effectiveness of principals, the indexes of model's goodness are given in Table 9. 
Table 9. The indexes presented for the model fitness obtained from LISREL software

\begin{tabular}{ccccc}
\hline Index & Index name & Standard rate & Test rate & Test result \\
\hline RMSEA & Root mean square error of approximation & $0.10<$ RMSEA & 0.08 & Confirmed \\
$a f$ & Chi-2/degree of freedom & $a f$ & 2.89 & Confirmed \\
GFI & Goodness of fit index & $0.90<\mathrm{GFI}$ & 0.90 & Confirmed \\
CFI & Comparative fit index & $0.90<\mathrm{CFI}$ & 0.98 & Confirmed \\
NFI & Non-normed fit index & $0.90<\mathrm{NFI}$ & 0.97 & Confirmed \\
\hline
\end{tabular}

Table 9 shows that the model's generality of the relationship between knowledge management and organizational learning with the effectiveness of principals was confirmed and it was based on a significant fit. Moreover, standard coefficients of the model represent a relationship between the variables as shown in Figure 1.

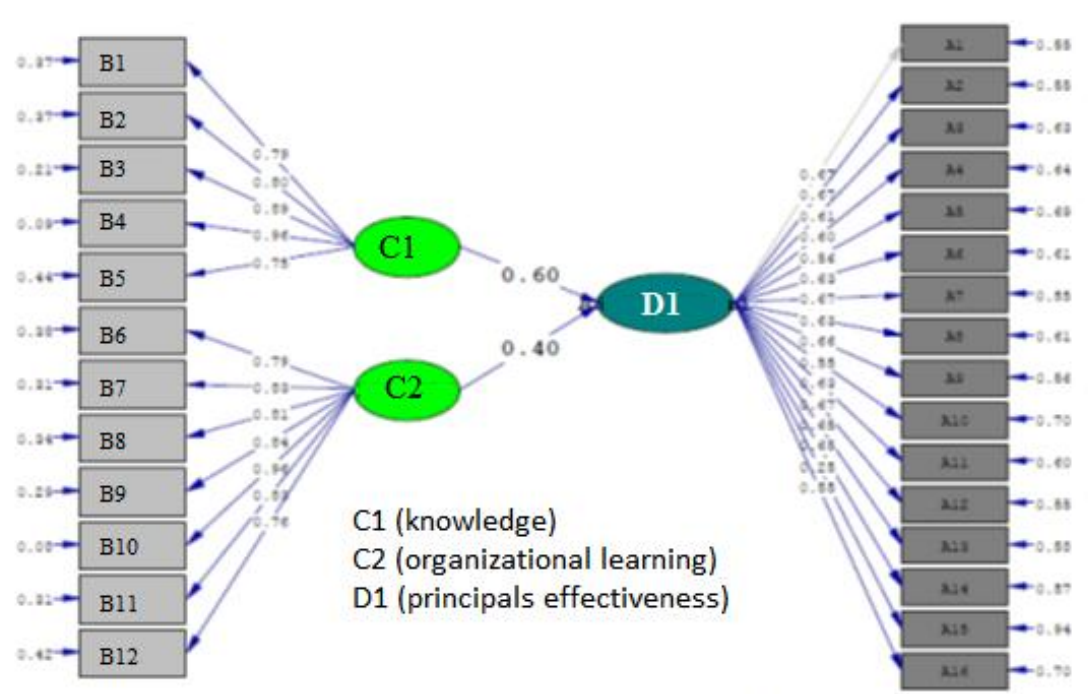

\begin{abstract}
B1 (Knowledge acquisition); B2 (Knowledge creation); B3 (Knowledge storage); B4 (Knowledge distribution); B5 (Maintain Knowledge); B6 (Common vision); B7 (Organizational culture); B8 (Teamwork Knowledge); B9 (collaboration); B10 (Systematic thinking); B11 (Leadership); B12 (Staff expertise)
\end{abstract}

Chi-Square-1007.61, df-348, P-value-0.00000, RMSEA-0.085

Figure 1. Measurement standard coefficient of LISREL software of knowledge management model and organizational learning with the principals' effectiveness

As is shown in Figure 1, the relationshipss among the variables are as follows:

There is a significant relationship between knowledge management and the principals' effectiveness in high schools of Zahedan with 0.6 coefficient at $99 \%$ confidence level.

There is also a significant relationship between organizational learning and the principals' effectiveness in the high schools of Zahedan city with 0.40 coefficient at $99 \%$ confidence level.

Moreover, t-values coefficient in the structural equations shows the confirmation or rejection of relationships among the variables. If it is more than 2, the relationship is confirmed; otherwise, it is rejected. T-values coefficients have been presented in Table 10 and Figure 2.

Table 10. t-values coefficients

\begin{tabular}{ccc}
\hline Variable & t-values & Approvability \\
\hline Knowledge Management & 5.40 & Approved \\
Organizational learning & 3.75 & Approved \\
\hline
\end{tabular}

As can be observed in Table 10 and Figure 2, t-values coefficients are more than 2 which indicate that the relationships among the model's variables are confirmed. 


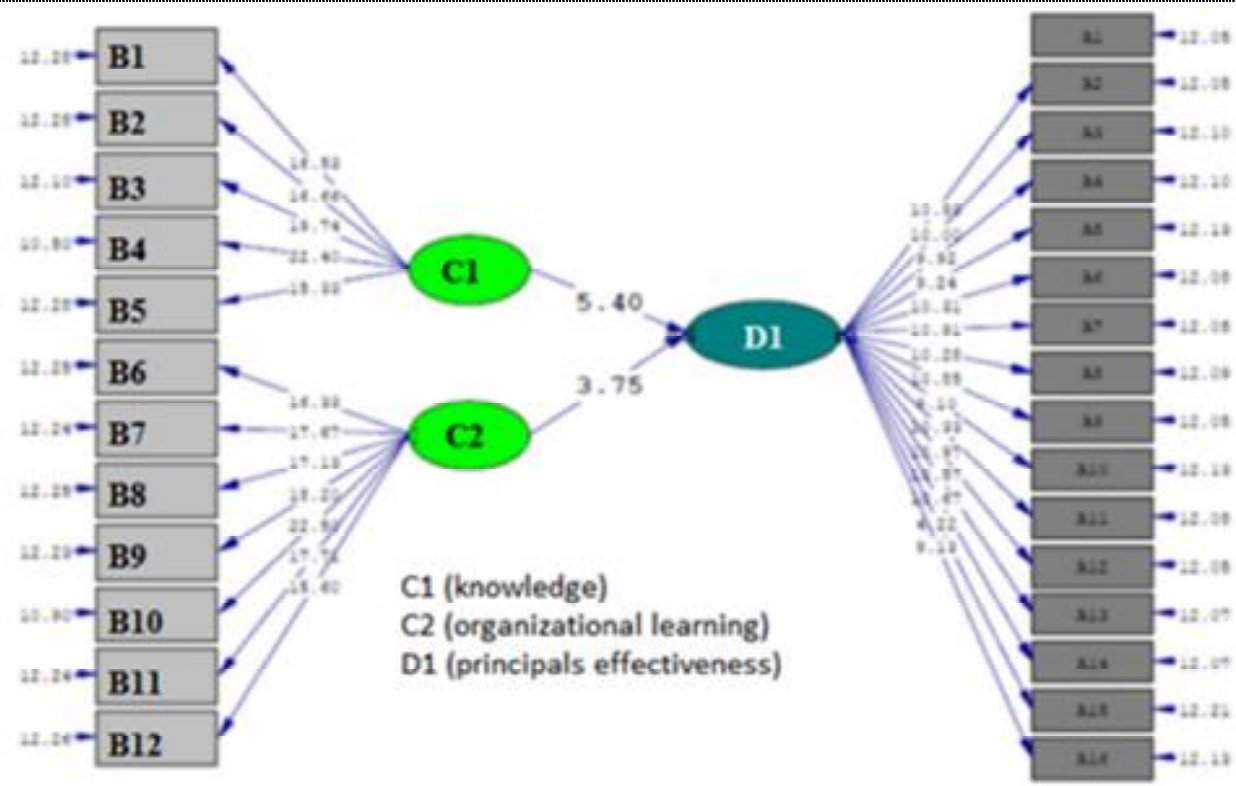

B1 (Knowledge acquisition); B2 (Knowledge creation); B3 (Knowledge storage); B4 (Knowledge distribution); B5 (Maintain Knowledge); B6 (Common vision); B7 (Organizational culture); B8 (Teamwork Knowledge); 89 (collaboration); B10 (Systematic thinking); B11 (Leadership); B12 (Staff expertise)

Chi-5quare-1007.61, df $=348$, p-valuem0.00000, Reszam-0.085

Figure 2: t-values coefficients of knowledge management and organizational learning models with the effectiveness of the principals' effectiveness

Research Question 3: Is there a difference between knowledge management and organizational learning and effectiveness of the principals with regard to the teachers' gender?

To examine the difference between knowledge management and organizational learning with the principals' effectiveness with respect to the teachers' gender, independent t-test was used. The obtained results are shown in Table 11.

Table 11. Results of independent t-test regarding the relationship between knowledge management and organizational learning with the principals' effectiveness with respect to gender

\begin{tabular}{|c|c|c|c|c|c|c|c|}
\hline Variable & Gender & Number & Mean & $\begin{array}{l}\text { Standard } \\
\text { deviation }\end{array}$ & $\begin{array}{l}\text { Degree of } \\
\text { freedom }\end{array}$ & $\mathrm{T}$ & $\begin{array}{c}\text { Significance } \\
\text { level }\end{array}$ \\
\hline \multirow{2}{*}{$\begin{array}{l}\text { Knowledge } \\
\text { management }\end{array}$} & Female & 151 & 70.68 & 12.74 & \multirow[t]{2}{*}{298} & \multirow[t]{2}{*}{2.37} & \multirow[t]{2}{*}{0.00} \\
\hline & Male & 149 & 66.88 & 14.97 & & & \\
\hline \multirow{2}{*}{$\begin{array}{l}\text { Organizational } \\
\text { learning }\end{array}$} & Female & 151 & 77.46 & 13.74 & \multirow[t]{2}{*}{2.98} & \multirow[t]{2}{*}{1.68} & \multirow[t]{2}{*}{0.00} \\
\hline & Male & 149 & 74.45 & 17.07 & & & \\
\hline \multirow{2}{*}{$\begin{array}{l}\text { Principals' } \\
\text { effectiveness }\end{array}$} & Female & 151 & 59.17 & 11.70 & \multirow[t]{2}{*}{298} & \multirow[t]{2}{*}{1.59} & \multirow[t]{2}{*}{0.00} \\
\hline & Male & 149 & 56.89 & 13.08 & & & \\
\hline
\end{tabular}

Results of Table 11 show that female principals with the mean of 70.68 have more knowledge management than male principals with the mean of 66.88 showing that this difference is significant at the level of $99 \%(t=2.37, d f=298$, $\mathrm{P}<0.01)$. Also, taking organizational learning into consideration, female principals have more organizational learning with the mean of 77.46 than male principals with the mean of 66.88 indicating that this difference is significant at the level of $99 \%(\mathrm{P}<0.01, \mathrm{df}=298$. $\mathrm{T}=2.37)$. Regarding the principals' effectiveness, female principals have more effectiveness with the mean of 59.17 than male principals with the mean of 56.89 showing that the difference is significant at the level of $99 \%(\mathrm{P}<0.01, \mathrm{df}=298, \mathrm{t}=1.59)$.

\section{Results and Discussion}

The main aim of this study was to review the relationship between knowledge management and organizational learning with the effectiveness of ordinary and smart secondary school principals in Zahedan city. The research method was analytical-correlational. The statistical community of the study was secondary school teachers of Zahedan city in that 300 ones were selected by stratified random sampling based on Morgan Table. 
In response to the first research question, the obtained data showed that there is a significant relationship between knowledge management and organizational learning. In other words, organizational learning increases by the increase of knowledge management. The components which predict knowledge management changes include knowledge storage, knowledge distribution, knowledge maintenance, knowledge acquisition and knowledge creation in that these relations in smart schools are more than that of ordinary ones. Components of knowledge management that predict organizational learning in smart schools are knowledge distribution, knowledge creation, knowledge maintenance and knowledge storage and the ones for ordinary schools are knowledge distribution, knowledge storage, knowledge maintenance and knowledge acquisition. The study conducted by Reshme (2009) showed that there is a significant difference between knowledge management and organizational learning in ordinary and smart schools. Moreover, she concluded that smart schools are above the average level and ordinary schools are below the average level. A similar study was also conducted by Moayeni (2006) in that the relationship between organizational learning and knowledge management at schools (public and private) was compared and it was found that the mean in private schools of Qom city, Iran, is more than its ordinary schools.

In response to the second research question, it can be concluded that the conceptual model was confirmed with respect to the introduced indexes in the structural equations. However, in his study, Yaghoubi (2009) concluded that today's organizations need effective and efficient employees to achieve their objectives for a comprehensive growth and development. Generally, the effectiveness and efficiency of organizations depend on the efficiency and effectiveness of human resources in that organization in which knowledge dissemination and creating a learning environment are the most important elements influencing the employees' performance. The study conducted by Maleki Nia (2009) showed that organizational learning is associated with adjusting the organization's behavior and its changes which uses new knowledge in the organization and is led to the organization's promotion.

In response to the third research question, it was found that female principals have higher average in knowledge management, organizational learning and its effectiveness in comparison with male principals. However, Yaghoubi's (2009) study found that female employees are more efficient than male ones. On the other hand, Zang's (2006) study showed that the set of male and female who are working in a group are more effective in the organization.

\section{Conclusion}

Today, the most important capitals of an organization are smart and knowledgeable employees that lead new technologies and service development of an organization to a stable competitive advantage by creating modern organizational processes. Innovative efforts in an organization are the result of investment in learning process and promoting human resource management and knowledge management. The organization makes it possible for the employees to rely on their own experiences with an innovative knowledge management and applying modern information technology and help organizational learning by growing in this regard. The organizations are successful in this respect if they consider knowledge as an asset and develop organizational values and norms that cause supporting the creation and collaboration of knowledge. The production and application of knowledge for the competitiveness and supporting organizations seem necessary. It must be considered that information processing technology is not the only component of knowledge management. The changes in decision-making model, organizational structure as well as the way of performing other issues are the components of management.

Given the obtained model in this study and various dimensions of knowledge management and organizational learning, the rate of effectiveness of principals in the specified roles in the table can be increased. Organizational learning and knowledge have a sublime position in that principals can manifest knowledge latent in human resources with an application of an effective management and hence deal with a non-secured and undesirable environment and cause organizational learning in schools for the organization's objective are implemented better and hence the principals' goals will be more effective. By having effective principals, we will have effective schools which is one of the important goals in education system. However, no special guideline can be recommended for the implementation of knowledge management and using organizational learning, but each principal can prepare the context to flourish knowledge regarding each particular circumstance and at least by sharing information among employees and an optimum use of their knowledge. When employees' knowledge is flourished, this great asset will create the context for organizational learning to achieve the educational organization's objectives as much the best way as possible and this means having an effective principals.

\section{Suggestions and Guidelines for Improving Educational System}

Given the questions raised in this study, the following suggestions can be presented to educational system:

1. Knowledge management system should be implemented and applied fully in the organizations and school principals.

2. Knowledge collaboration among the employees should be increased which causes more learning among individuals.

3. Employees' experiences and expertise should be formed in a systematic structural framework in order to be used for solving organizational problems in its due time.

4. Specific situations should be provided for flourishing inventive and innovative employees' talent.

5. Level of employees' knowledge should be increased and as a result, organizational learning and effectiveness promotion will be increased among them. 


\section{References}

Argot, I. (2003). Organizational learning and strategic change research in multi - level issues, Activeness London Rout.

Beikzade, G. \& Fardiazar, A. (2010). Study of the effective organizational factors on organizational learning of area 8 of fuel transmission operation. Scientific-Research Journal of Human Management and Resources, 38.

Chang, V. (2008). How does knowledge management influence innovation and competitiveness. Journal of knowledge management, 9 (3).

Daft, R. (2008). Toward model of organizations as interpretation systems. Academy of management preview, 9 (2).

Ghorbanizade, M. (2008). Construction and validation of a scale to measure organizational learning process, Monthly Journal of Knowledge and Behavior, 29.

Hajipour, B. (2007). Prioritizing kinds of organizational culture (based on Queen model) in terms of the rate of their effectiveness on organizational learning. Monthly Journal of Strategic Management Thought, 5.

Khanalizad, R. (2010). Study of the relationship between empowerment and organizational learning. Evolution Management Research, 3.

Loran's J. (2002). Synergizing the learning organization, Journal of knowledge management, 6 (3).

Machlup, F. (1999). Knowledge metrics for measuring intellectual capital. Journal of intellectual capital. 1(1).

Malekinia, A. (2009). Knowledge management in learner organization. Research Training Journal of Tadbir, 182.

Martin, B. (2009). Knowledge management within the content of management. Singapore Management Review, 2.

Moghimi, M. (2011). Knowledge management and information technology. Issue 1, Tehran, Rahdan Publications.

Mulgan, G. (2011). Government, knowledge and business of policymaking. Journal of Public Administration and Policy Research, 3(1).

Nanda, K. (2007). Study of the process of organizational learning in software films in India, Jechnovation, 23.

North, D. (2008). Institutional change and economic performance, Cambridge: Cambridge University Press.

Nourizian, M. (2010). Knowledge management. Research Training Journal of Tadbir, 179.

Remshe, G. (2009), Studying and comparing knowledge management and organizational learning in ordinary and smart schools of Tehran. Journal of Training Research, 40.

Rodan, S. (2002). Innovation and heterogeneous knowledge in managerial contact networks. Journal of Knowledge Management, 6 (1).

Saban, K. (2001). Organizational learning as a critical component to new product development. Journal of Product Innovation Management, 8 (1).

Saedi, M \& Yazdani, H. (2009). Proposing a procedural model for the implementation of organizational learning-based knowledge management in Iran Khodro, data-based theories. Journal of Information Technology Management, 2.

Sobhaninejad, M. (2008). Learner organization. Tehran, $1^{\text {st }}$ publication, Sitroun Publication.

Tuomi, I. (2007). Networks of innovation: Changing a meaning in the age of Internet. The future or knowledge management lifelong in Europe, 4 (2).

Yaghoubi, M. (2009). Study of the relationship between organizational learning components and knowledge management in chosen hospital staff in Isfahan city. Monthly Journal of Health Management, 42.

Yang, J. T. (2004). Qualities of knowledge creating company: How Sappiness companies create the dynamics of innovation. New York: Oxford University Press. 